\title{
Tortoises $v$. Rats and Goats in the Galapagos
}

Each of the larger islands of the Galapagos has (or had) its own subspecies of giant tortoise. Today ten are known to survive, but two are in serious danger, one of them, on Isla Pinzon (Duncan)*, because introduced black rats eat the young. To save them the Charles Darwin Research Station has successfully reared young tortoises in the station and will this year return 29 four-year-olds (which are large enough to cope with the rats) to their native island. A new tortoise-breeding centre was built last year, and the work is being extended. This article, which describes the rearing programme and comments on the general tortoise situation in the Galapagos, is based on information supplied by Roger Perry, the retiring Director, who has been largely responsible for this successful breeding programme. An article on the Galapagos tortoises by Dr David Snow, a former Director of the CDRS, was published in ORYX, December 1964.

In 1965 the giant tortoises on Isla Pinzon (Duncan) in the Galapagos appeared to be heading for extinction. No young tortoises could be found when scientists of the Charles Darwin Research Station searched the island; the youngest appeared to be not less than 30 or 40 years old. The reason was that introduced black rats were killing the young hatchlings. The Director of the Station, Roger Perry, decided to breed them at the Station. Eggs were collected, hatched in an incubator, and the hatchlings reared in converted bird cages. Now five years later, Roger Perry reports, 29 tortoises reared from the first batch of eggs are large enough to defend themselves against the rats and are to be returned to Pinzon at the end of this year.

Once the method had been proved practicable, and over a hundred young had been reared in this rather primitive way, it was decided, with the full support of the Ecuadorian Government, to extend the programme. With a grant from the San Diego Zoological Society the station manager, Rolf Sievers, last year designed and erected a new building, with running water and central heating (necessary for the young tortoises in the misty garua season) and new incubators and rearing pens were installed. Opened in January this year, the new centre houses I03 young tortoises ranging from a few weeks old to four years, including the 29 about to be returned to Pinzon. There are also four from Isla Española (Hood) where numbers have long been depleted and are now dangerously low, thanks to large numbers of (introduced) feral goats (which eat the tortoises' food) and poaching by fishermen over many years; not more than seven have been found in recent years, so three females and a male were taken to form a breeding unit. Although this

* Almost all the Galapagos islands have at least two names-one English, one Spanish, and the former are used in the scientific literature. This article uses the Spanish names, but both are on the map. 


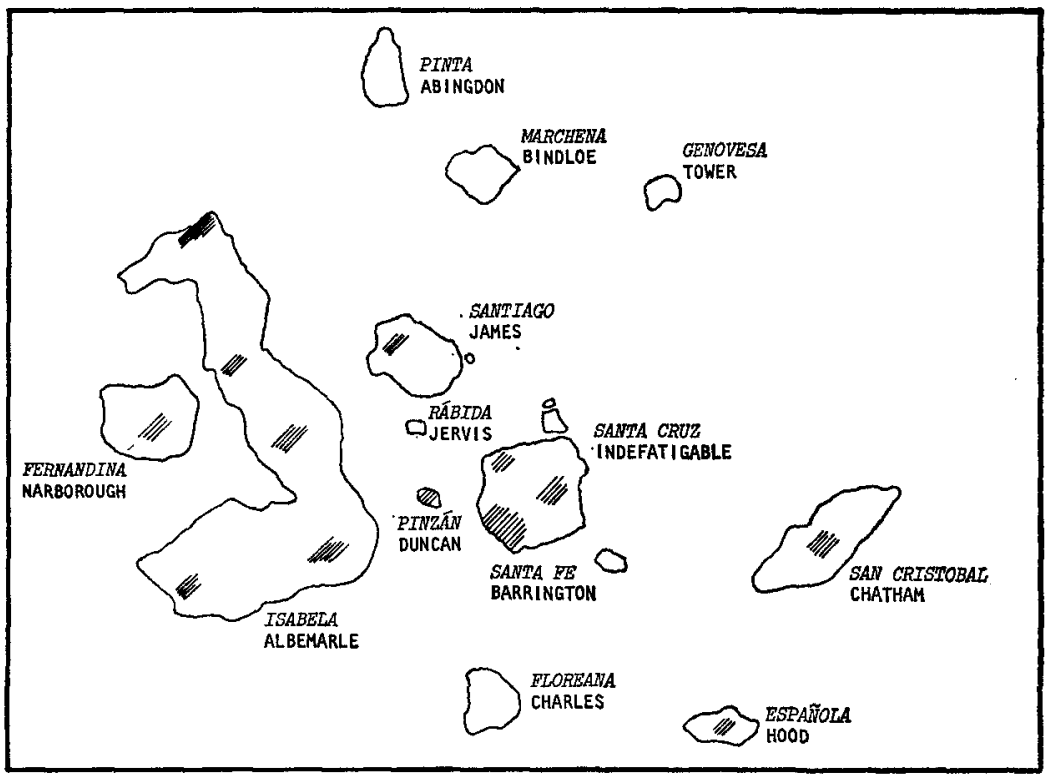

was done after the breeding season peak, one female laid eggs but they did not hatch. With the facilities of the new centre it is hoped that next season the Española tortoises will be more successful.

The centre is open to visitors, which is valuable for getting the support and goodwill of the Galapagos islanders, and also for educational groups. Panels on the walls explain, in Spanish and English, the tortoiserearing programme and the status of the tortoises on the various islands. Two scientists, Dr Craig MacFarland and Dr William Reeder, are studying the ecology and breeding biology of the Galapagos tortoises and their findings should provide guidelines for the rearing programme.

Of the original fifteen subspecies or races of Galapagos tortoise, five are on the largest island, Isabela, each having evolved in the isolation of one of the island's five great volcanoes, and ten occurred on separate islands. On only one of these-Isla Pinta, where tortoises survived into the 1950 - -have they become extinct in very recent times. On Floreana and Santa $\mathrm{Fe}$ the tortoises disappeared a century or more ago; and the tortoise of Rabida, which as far as anyone knows never had very good grounds for being considered a separate subspecies, no longer exists. On Santa Cruz, San Cristobal, Santiago, Pinzon and Española, the native tortoises survive in remote areas, but all are threatened in one way or another by introduced animals and, to a lesser and decreasing extent, by hunting and poaching. The fifteenth race, from Fernandina, is a mystery. Only one, an old male, has ever been found on the island, by Mr Rollo Beck in 1906; before that none had been reported. Taken and skinned by moonlight by $\mathrm{Mr}$ Beck, it is today in the museum of the California Academy of Sciences with the name to itself of Geochelone 
elephantopus phantastica. None has been found on the island since, despite several searches and a report of tortoise droppings in 1964. It is just possible, though very unlikely, that a population may still survive on the remote southern slope of the volcano, but whatever happened to the Fernandina race was not due to man, for the island has never been inhabited or suffered from introduced animals. It may be that volcanic activity destroyed a once flourishing race.

Like so many other oceanic islands, the Galapagos have suffered badly from repeated and thoughtless introductions of animals by man. Feral pigs, dogs and rats are a major threat to the young of several races of tortoise; and feral donkeys and goats not only compete for the available food but have started regressive trends in the vegetation of practically all the lower-lying areas of the islands where they occur. Perhaps the most dramatic commentary on this is provided by the small northern island of Pinta, the only outlying island to have had its own tortoise. In 1958 the first goats, a male and two females, were released from a fishing boat, to provide fresh meat for the fishermen's future visits. Ten years later, in August 1968, a team from the Darwin Station estimated their numbers at between four and five thousand. Multiplying without check or control, they had cleared stretches for half a mile or more where before vegetation had been continuous and almost closed, and seven or eight plant species, unique to the Galapagos, had over the same time virtually disappeared from the island.

\section{Creation of the National Park}

The present efforts to save the Galapagos tortoises started in 1959, when the Government of Ecuador declared all uninhabited areas of the islands a National Park, and required full protection to be given, among other species, to the giant tortoises. This was the culmination of years of dedicated work by the great Belgian conservationist, Dr Victor van Straelen. The law has been moderately successful. Protection of the tortoises has, on the whole, been rigorously enforced, bearing in mind the scattered nature of the islands and the difficulties facing the Ecuadorian authorities in ensuring adequate inspection and control. But little progress has been made in preventing the extension of the farmlands on the largest islands into the national park. The saving grace, as far as the tortoises are concerned, has been and will doubtless remain the unsuitability of much of the terrain for human settlement.

In the same year, 1959, the Charles Darwin Foundation came into being as an international organisation devoted to scientific study and conservation in the archipelago, and was entrusted by the Government of Ecuador with the establishment and running of a biological station in the islands, the Charles Darwin Research Station. Initial surveys quickly showed that the tortoises were seriously threatened, and that information was required urgently on the status of surviving races. A system of marking and numbering the animals was begun, and, gradually, with more information on the different populations, a more coherent picture emerged of the management programmes that should be adopted. (See ORYX, December 1964). Tortoises are only numerous in two areas: 


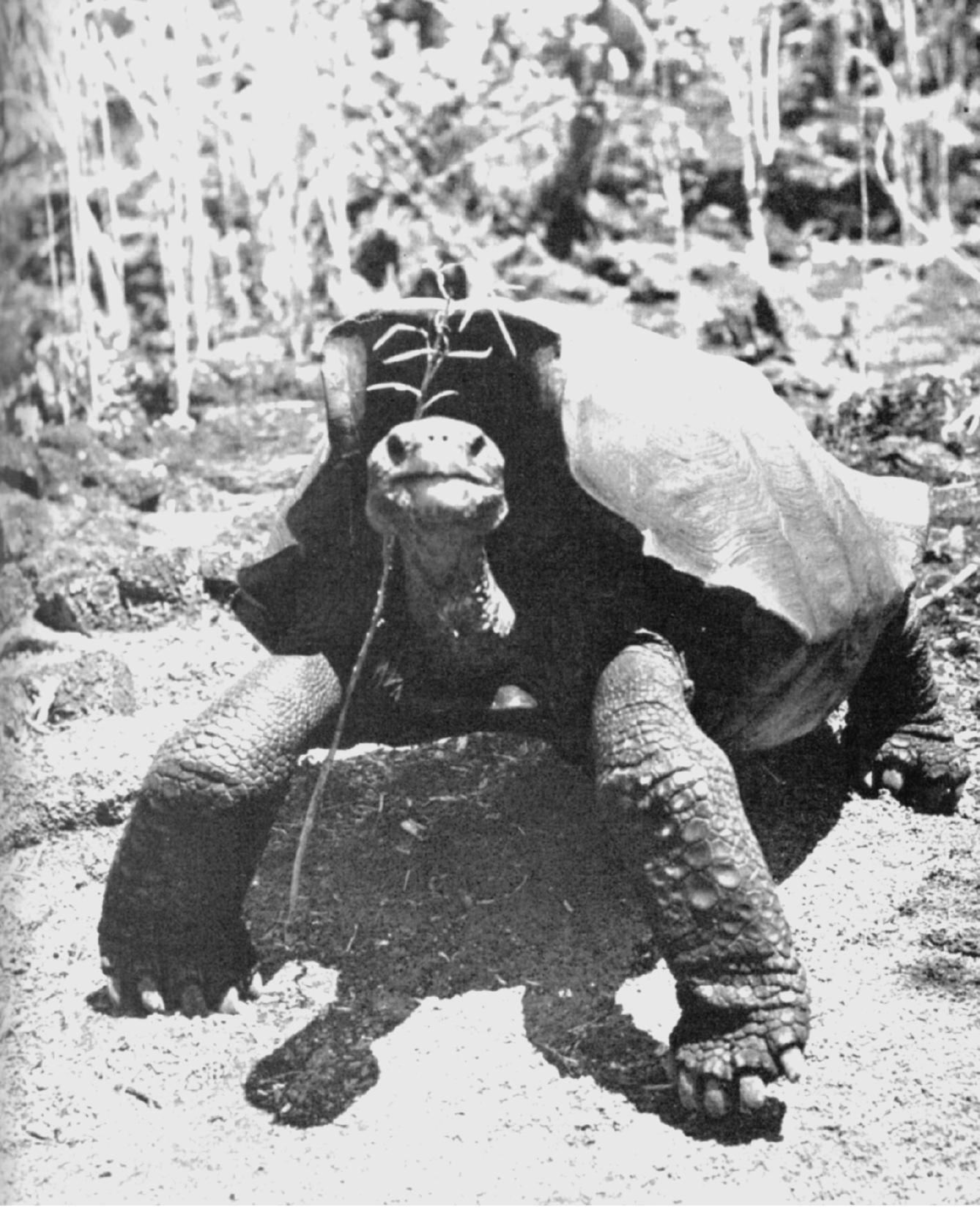

Plate 3

GALAPAGOS TORTOISES. Eric Hosking meets a giant tortoise from Isla Española (Hood) at the Charles Darwin Research Station on Santa Cruz. The Española race of tortoises is in serious danger of extinction, and last winter four were taken to the Station to form a breeding unit, with a view to returning young tortoises later to the island. All the tortoise photographs, plates $9-13$, were taken by Eric Hosking. 


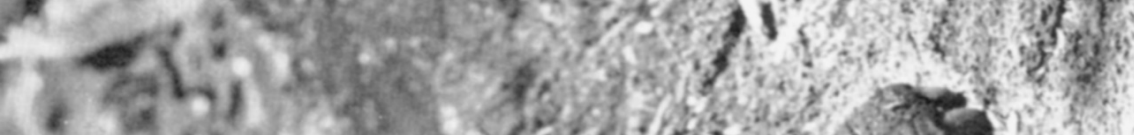

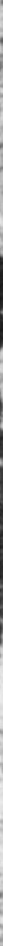

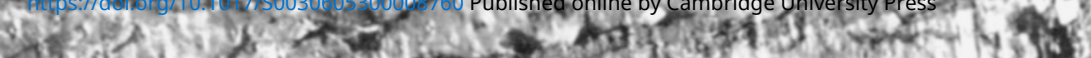




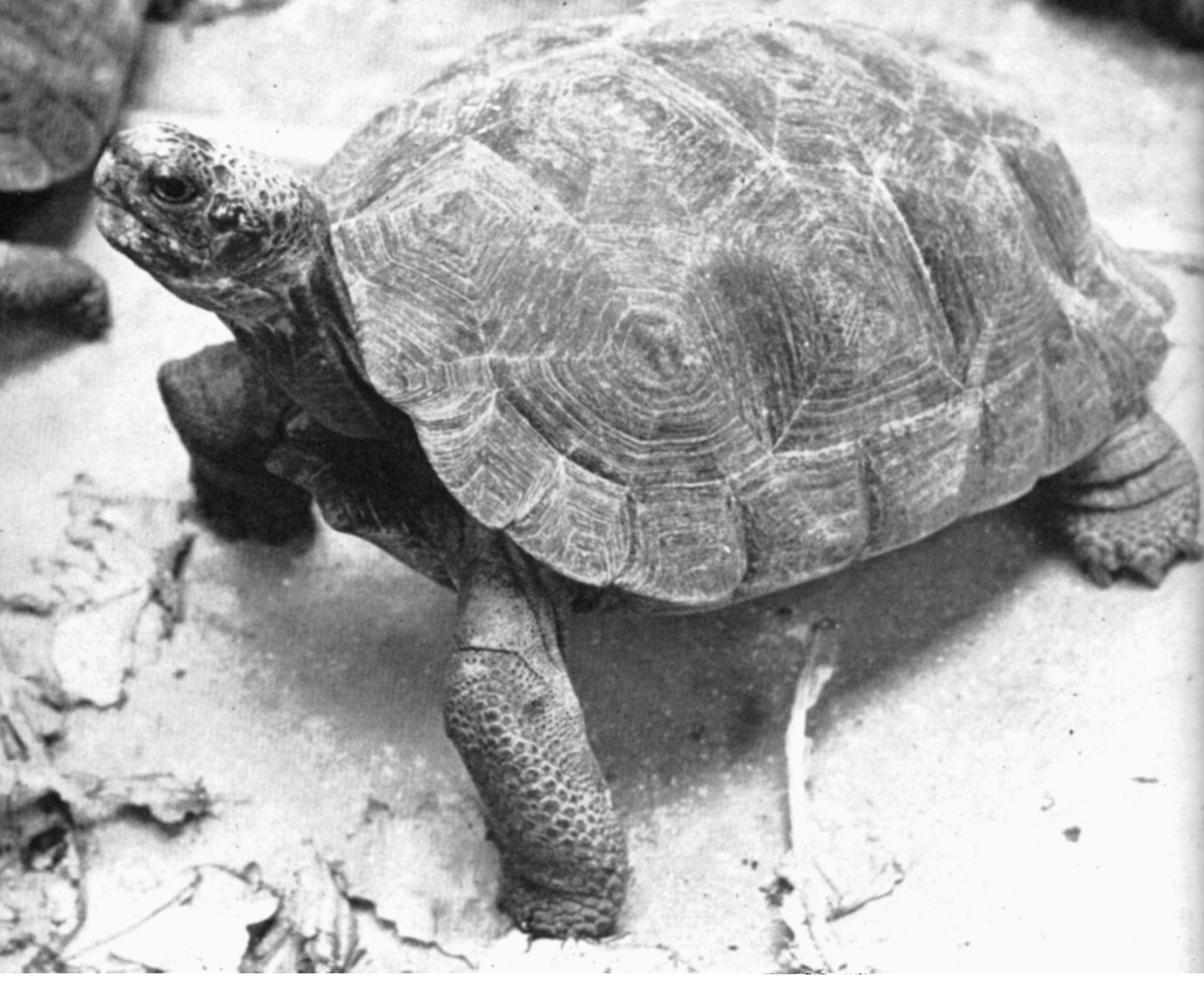

Plates 6 \& 7

OLD ENOUGH TO GO HOME-two of the Pinzon tortoises bred at the Research Station. Now big enough to withstand the rats, they are to be returned to the island this autumn.

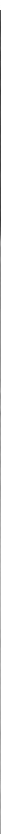


on Volcan Alcedo, the middle, and active, volcano on Isabela, and in the south-western part of Santa Cruz, with a population on each of not less than two to three thousand animals. In 1963 the main tortoise range on Santa Cruz, some sixty-four square miles, was set aside as a strict reserve.

Over one hundred tortoises of five other races have now been found and marked: from Sierra Negra and Cerro Azul on Isabela, San Cristobal, Santiago, and Pinzon, and there is growing evidence that the two northern races of Isabela, on the volcanoes of Wolf and Darwin, survive in at least potentially viable numbers, but northern Isabela is among the least known areas of the archipelago. On Española alone, with only seven individuals seen in recent years, is the tortoise considered to be in immediate danger of extinction.

Today, wardens, working under conservation officials of the Galapagos National Park Service (part of the Forestry Service of Ecuador), are permanently based among tortoise populations on Santa Cruz and southern Isabela. Feral pigs are hunted in tortoise nesting areas, a systematic attempt is being made to exterminate wild dogs which range over Cerro Azul, and local hunters are subsidised, with funds from Quito, and encouraged to hunt wild-running pigs. It is planned to station wardens on Santiago to shoot pigs from July to October, the tortoises' laying time. Periodic visits to Española keep the goats there under some semblance of control. Because the feral goats provide the islanders with fresh meat the impossible task of exterminating them is not even attempted; greater advantages lie in the more acceptable course of control in critically affected areas. Finally, it is hoped over coming months to look into ways of exterminating the introduced black rats that are preventing successful breeding of the tortoises on Isla Pinzon.

\section{Turtle Slaughter in Mozambique}

The outlook for sea turtles in southern Mozambique is very unpromising, reports George Hughes who is doing a turtle survey in the south-west Indian Ocean. The coastal people remove every egg and kill any turtle they see, despite legal protection of which there is no enforcement. In Natal, however, the Parks Board has accepted his recommendation for a turtle reserve in Tongaland.

\section{Komodo Dragon Numbers}

The number of Komodo dragons, as the world's largest lizard is commonly called, was put at between 1000 and $\mathrm{I}$ I00 last summer by Wayne King, Curator of Herpetology for the New York Zoological Society which is financing a study of these formidable lizards, found only on four small Indonesian islands of which Komodo is one.

\section{British Mammal Charts}

Six attractive and effective full-colour wall charts illustrating 59 British mammals are published by Warnes in association with the Mammal Society. In two sizes, the large $(20 \times 30$ ins) costing $7 \mathrm{~s}$ each, the small $\left(8 \frac{1}{2} \times 12\right.$ ins) IOs for a set of six. Notes are supplied with each. The six are: Insectivores and small rodents; Large rodents and lagomorphs; Bats; Carnivores; Marine mammals; and Deer. 